\title{
Assessment of Prevalence of Primary Dysmenorrhoea in University Students
}

\author{
Research Article
}

\section{Pranali Boharupi ${ }^{1}$, Meena Shamrao Deogade ${ }^{*}$}

\author{
1. Ayurvedic Student, Department of Dravya Guna, \\ Mahatma Gandhi Ayurved College Hospital and Research centre, Wardha, Maharashtra, India \\ 2. Associate Professor, Department of Dravyaguna, All India Institute of Ayurveda, New Delhi. India
}

\begin{abstract}
Severe menstrual pain which is restricts to normal activities is termed as dysmenorrhoea (kashtartava). Today's sedentary lifestyle and food habits are responsible for this problem worldwide. Dysmenorrhoea ensuing discomfort for women's daily routines and resulting in missing work, college or school, inability to participate in sports or other activities. Primary dysmenorrhoea (PD) is the most common gynaecological problem among menstruating young adults and adolescents. To determine the prevalence of PD in university students questionnaire based survey was carried out in DMIMS (DU). Data of 500 female students was collected. Due to invalid data, 49 students were exempted. It is observed that 409 girls $(90.68 \%)$ out of 451 were found suffering from dysmenorrhea. Out of that $74.08 \%$ girls are likes to eat spicy/junk food and $49.87 \%$ suffering from anxiety/depression. Food habits and stress may be the cause of this problem. Further detail study on big sample size needed for evaluation of cause of dysmenorrhea in young female students.
\end{abstract}

Key Words: Primary dysmenorrhoea, Kashtartava, University students.

\section{Introduction}

Menstruation is a natural event as a part of the normal process of reproductive life in females. Menstrual pain which is severe enough to limit normal activities is termed as dysmenorrhoea (kashtartava).Due to today's lifestyle and food habits, dysmenorrhoea is becoming today's burning problem throughout the world which ensuing discomfort for women's daily routines and resulting in missing work, college or school, inability to participate in sports or other activities. About $25-50 \%$ of adult women and about $75 \%$ of adolescents experience pain during menstruation, with $05-20 \%$ reporting severe dysmenorrhoea (1).

Primary dysmenorrhoea (PD) is the most common gynaecological problem among menstruating young adults and adolescents. (PD) is defined as a cramp-like pain in the lower abdomen at the onset of menstruation without any identical pelvic pathology. Pain may be accompanied by back pain, nausea, vomiting, blotting, breast tenderness and diarrhoea. Besides being a gynaecological problem, PD is an important health problem concerning public health, occupational health and family practice, as it affects both the quality of life and the national economy due to

\section{* Corresponding Author:}

\section{Meena Shamrao Deogade}

Associate Professor,

Department of Dravyaguna,

All India Institute of Ayurveda, New Delhi. India

Email:_drmmeena@rediffmail.com short-term school/college absenteeism and loss of labor (2).

Kashtartava (dysmenorrhoea), in the Ayurveda described under AstaArtavaVyapad(eight menstrual problems) and the predominant factor is Vata. Apanavata is the governing force of menstruation; its vitiation gives rise to many diseases like yonivyapad's(vaginal problems) or Artava. Udavartini being one among yonivyapad's in which vitiated Vata moves in reverse direction leading to 'painful menstruation'.(3).

The prevalence of dysmenorrhoea is $54 \%$ (53\% in girls in urban areas and $56 \%$ in girls in rural areas). Sickness absenteeism (28-48\%), socio economic losses, and perceived quality of life losses are more prevalent among girls in urban areas than in girls in rural areas. Girls in rural areas resort to physical labor and other natural methods to obtain relief while the girls in urban areas are mainly depending on medications (4). So that in this study, it was intended to examine the cause, attitudes and behaviour of female students of only one university to this problem.

\section{Materials and methods}

The female students of 18 to 25 age group from DMIMS (Deemed to be University), Sawangi (M), Wardha were selected on the basis of history and questionnaire. Female students below 18, above 25 ages, known cases of any pelvic pathology and students on any hormonal treatment were excluded from the study, whereas students who are given consent, suffering from menstrual pain and unmarried included. This Study comprised of questionnaire. Questionnaire made with the guidance of previous work done by Aytac 
Polat et al. in 2009. Questionnaire included closed ended and open ended questions and each and every participant had to answer this questions. The data collection was started after the clearance from Institutional Ethics committee. Institutional Ethical Committee (IEC) clearance letter No. DMIMS(DU)/ IEC/Sept-2019/8459 dated 10.10.2019. An interview based interaction was done on the basis of questionnaires with maximum 7 - 8 female students/ day. And their respective answers had been noted and evaluated.

\section{Observations and Results}

This study was conducted at Datta Meghe Institute of Medical Sciences (Deemed to be university), Sawangi (M), Wardha. Data of 500 female students from Medical, Dental, Ayurveda, Physiotherapy and Nursing was collected. Data of 49 students were exempted from study because of invalid data. However, 409 girls $(90.68 \%)$ out of 451 were found suffering from dysmenorrhea. The data of 409 girls analysed as follows.

$24.20 \%$ girls from Ayurveda, $\quad 28.85 \%$ from dental, $12.95 \%$ from medical, $10.02 \%$ from physiotherapy and $23.96 \%$ from nursing who are suffering from dysmenorrhoea i.e. Kashtartava (graph-1). On the basis of age group it is found that $15.15 \%$ students of 18 year age, $27.87 \%$ students of 19 years age, $16.13 \%$ students of 20 years of age, $25.91 \%$ was 21 years of age, $7.57 \%$ of 22 years, $4.15 \%$ of 23 years, $2.20 \%$ of 24 years, and $1.02 \%$ students of 25 years are suffering from dysmenorrhoea (graph-2). 91.93\% participants belonging to the Hindu, $4.88 \%$ to Muslim, $2.20 \%$ are Christian and $0.97 \%$ were others religion (graph-3). These girls also from $28.15 \%$, $5.76 \%, 64.07 \%$, and $1.99 \%$ were from higher middle, higher, middle and poor family respectively (graph-4). $74.08 \%, 1.22 \%$, and $2.44 \%$ girls like to eat spicy/junk food, smoking and consume alcohol respectively (graph-5). 11.75\% students having less sleep $(<6 \mathrm{hrs})$, $78.97 \%$ girls having $6-8$ hours sleep, however $8.06 \%$ students having $9-10$ hours, and $1.22 \%$ students having 11-12 hours and even more (graph-6). 49.87\% girl having feeling of anxiety/depressed/angry, however $55.42 \%$ students doing are exercise regularly (graph-7). Out of that $35.47 \%, 1.99 \%, 10.20 \%$, and $7.76 \%$ preferred walking, aerobics, gym exercises and other type of exercises like yoga, spots etc respectively. Whereas $44.58 \%$ students not performing any type of exercise. Menarche found at the age of $9-0.24 \%$, at the age of $10-1.22 \%$, at the age of $11-4.40 \%$, at the age of $12-15.89 \%$, at the age of $13-24.69 \%$, at the age of $14-31.05 \%$, at the age of $15-15.15 \%$, at the age of 16 $-5.13 \%$, at the age of $17-1.95 \%$, and at the age of $18-$ $0.24 \%$ (graph-8). $0.24 \%, 5.62 \%, 9.77 \%, 35.26 \%$, $33.74 \%, 8.80 \%, 1.95 \%, 1.95 \%, 0.97 \%, 1.22 \%, 0.24 \%$, $0.24 \%$ girls having cycle of $15,20,25,28,30$, $35,40,45,50,60,70$ and 90 days respectively (graph-9). 2- 3 days, $4-5$ days, $6-7$ days, and $8-10$ days and 14 days length of menstruation was observe in $7.57 \%$, $70.68 \%, 19.80 \%, 1.71 \%$, and $0.24 \%$ participants respectively (graph-10). Normal menstrual bleeding observed during menses in $80.44 \%$, whereas Scanty in $6.84 \%$ and Heavy in $12.70 \%$ (graph-11). Whereas $4.40 \%$ girls uses $1,39.60 \%-2,38.14 \%-3,11.98 \%-4$, $3.66 \%-5,1.46 \%-6$, however 8,9 , \& 10 pads used by $0.24 \%$ (each) girls per day (graph-12). The girls have got knowledge regarding menstruation is $78.48 \%$ from mother, $11.49 \%$ from friends/siblings, $4.64 \%$ from Media (Books/ TV), 5.13\% from medical person and $0.26 \%$ included in other (graph-13).

$57.88 \%$ girls were aware about their mother's menstruation history. Out of that $58.53 \%, 11.75 \%$, 9.53\% girl's mother having regular, irregular and might be regular menstruation. $45.23 \%$ mothers of participants were graduate, $21.72 \%$ participant's mothers were post graduate, $7.31 \%$ mothers was pre-school, whereas $25.49 \%$ mothers were high school and $0.22 \%$ were mentioned as other. $52.56 \%, 62.35 \%, 48.65 \%, 26.15 \%$, $32.02 \%, 56.72 \%$, and $36.91 \%$ girls are suffering from associated symptoms like mood swings, fatigue, bloated abdomen, nausea/vomiting, breast tenderness, loss of appetite/hunger and loose motions/upset bowels respectively (graph-14).

Further analysis was conducted to find out that girls are suffering from since how long, then it was observed that $33.74 \%, 16.13 \%, 17.35 \%, 13.20 \%$, $10.26 \%, 3.42 \%$, and $0.97 \%$ girls having menstrual pain (Dysmenorrhoea/Kashtartava) since menarche, in alternate months, every month after some period of menarche, since $1-2$ years, since $3-4$ years, since 5 6 years, since $7-8$ years, and since $9-10$ years respectively. It was also found that some girls were recently suffering from dysmenorrhoea as $0.97 \%$, $2.93 \%, 0.24 \%, 0.73 \%$ since $1,2-3,4-5$ months respectively (graph-15). Pain was started on very first day of menses in $71.88 \%$ girls however $17.35 \%, 2.19 \%$, $3.65 \%$ second, third and fourth day of menses respectively, whereas $4.88 \%$ girl was suffering from the day before menstruation starts. Duration of pain was observed as $1-2 \mathrm{hrs}$ in $15.39 \%, 3-4 \mathrm{hrs}$ in $12.22 \%$, 5-6 hrs in $10.75 \%, 7-8 \mathrm{hrs}$ in $3.42 \%, 12 \mathrm{hrs}$ in $17.35 \%, 24$ hrs in $18.58 \%, 48 \mathrm{hrs}$ in $15.64 \%$ and $72 \mathrm{hrs}$ in $6.11 \%$, and $96 \mathrm{hrs}$ in $0.48 .21 .76 \%$ consumed medicine for intolerable pain during menstruation and $31.05 \%$ participants visited physician for the same. $21.76 \%$ girls reported that their menstruation disturbed due to medication (Graph-16).

$21.76 \%$ girls were missed their collage activities in last 12 months, $3.17 \%$ participants misses their internal final examinations in last academic session, however $26.39 \%, 52.32 \%$ and $31.53 \%$, 53.78\% girls showed poor and average college as well as life performance during menses (Graph-17). Asked the girls assess the intensity of menstrual pain with the help of Visual Analogue Scale (VAS). 13.44\%, 47.41\%, $15.15 \%, 6.35 \%$ and $6.6 \%$ girls have been given score as $6,7,8,9$ and 10 respectively (graph-18).

\section{Discussion}

The normal menstruation is that which has inter menstrual period of one month, duration of blood loss as five days, is not associated with pain or burning sensation, excreted blood is not unctuous, not very 
scanty or excess in amount, colour resembles the red juice of laksha, red lotus flower, fruit of jequirity or rabbit's blood (5). In ancient time women were not suffering much from Kashtartava because they were followed the Ritucharya and Rajasvalacharya very precisely. So that Kashtartava (dysmenorrhoea) is not described as a separate disease in Ayurveda but it is a symptom of many other diseases. From the observations and results it is found that $90.68 \%$ girls were having painful menses i.e. suffering from dysmenorrhoea and out of that $33.74 \%$ girls having intolerable pain since menarche. Pain was started on very first day of menses in $71.88 \%$ girls and $52.81 \%$ girl needs medical assistance either by medicine or by physician's advice. $79.11 \%$ affects the performance. Maximum girls were regularly suffering from associated symptoms like mood swings, fatigue, bloated abdomen, nausea or vomiting, breast tenderness, loss of appetite or hunger and loose motions or upset bowels respectively (graph-14).

$70.50 \%$ girls liked to take spicy and junk food this type of food habit aggravates the vata and pitta which is responsible for painful or abnormal menses. Ayurveda considers Ahara (food) as one of the three supporting pillars. Mind and body affected by diet. It is affecting our body due to its long and continuous use. Therefore our ancient Acharyas have given a lot importance to it. And they have been mentioned that unwholesome diet is the cause of disease. At the end of digestion, ingested food transformed into ahara rasa. This ahara rasa nourishes body, mind and sensory organs. Therefore not only physical health but also mental well being and spiritual progress all are depend on food. Health as well as the disease is caused by the Ahara (6). 46.56\% students not performing any type of exercise and $13.39 \%$ girl has taken more sleep (11-12 hrs). Sedentary lifestyle and lack of exercise is one of the reasons of dysmenorrhoea because it causes avarodha (obstruction). $49.87 \%$ girl had feeling of anxiety, depression or anger, $11.75 \%$ students having less sleep. It means dysmenorrhoea may be associated with anxiety or depression also. This is also the cause of vitiation of vata. Vata is responsible for the regulation of menses and is the main responsible factor, though other doshas only be present as anubandhi (association) to it. So pain is produced due to vitiation of only vata dosha or in combination with other doshas. Therefore associated symptoms like mood swings, fatigue, bloated abdomen, nausea or vomiting, breast tenderness, loss of appetite or hunger and loose motions or upset bowels are also observed in participants. Ayurvedic acharyas specifically mentioned that, in the management of any yoniroga, vata dosha has to be normalized initially.

\section{Conclusion}

Maximum girl students are of university suffering from dysmenorrhoea. Sedentary lifestyle, food habits and stress as well as not follows the regimen during menses may be the reason. Therefore, there is need to sensitize the youngsters (female) about rajahsvalacharya described in ancient Ayurveda literature which was followed by people in previous years as a customs.

\section{References}

1. Deogade M S, Efficacy and comparison of ShatapushpaTaila Matrabasti with Shatapushpa Churna in Kashtartava (Dysmenorrhoea), DMIMS (DU); 2018

2. Aytac Polat et al., Prevalence of primary dysmenorrhea in young adult female university students, arch gynacol obstet, 2009, 279; 527-532

3. ibid 1

4. Atchuta Kameswararao Avasarala and Saibharghavi Panchangam, Dysmenorrhoea in Different Settings: Are the Rural and Urban Adolescent Girls Perceiving and Managing the Dysmenorrhoea Problem Differently?, Indian J Community Med. 2008 Oct; 33(4): 246-249

5. ibid 3

6. Holani S, Deogade M S, Association of Amla Rasa in Kushtha Vyadhi (Skin disorders), International Journal of Research in Ayurveda and Medical Sciences 2019; 2(2);

\section{Graphs}

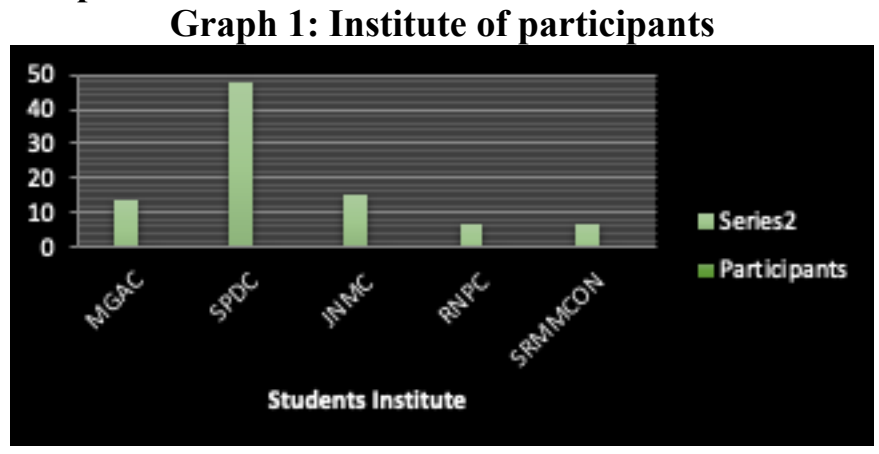

Graph 2: Age of participants

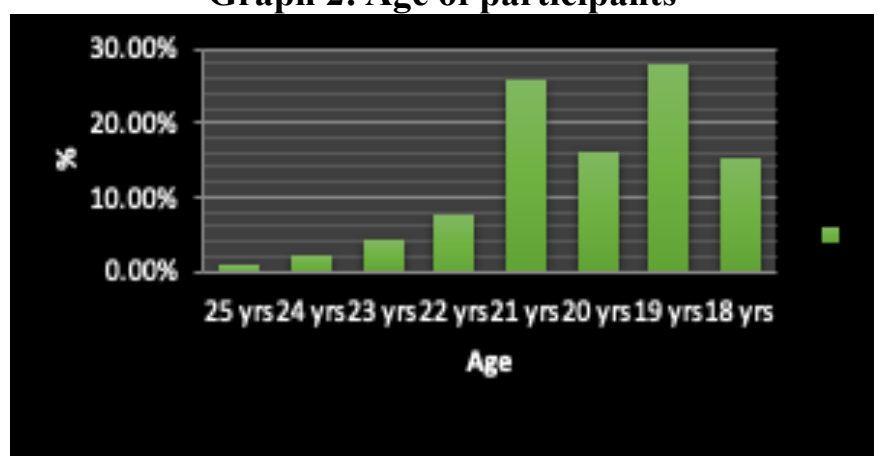

Graph 3: Religion of participants

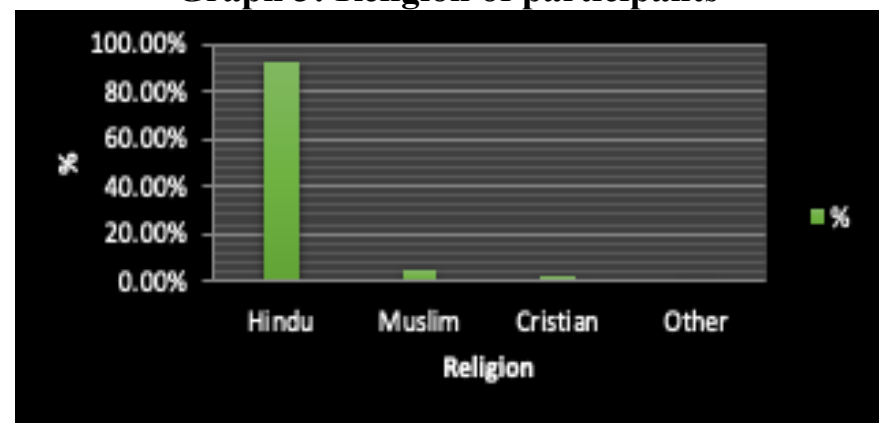


Pranali Boharupi et.al., Assessment of Prevalence of Primary Dysmenorrhoea in University Students

Graph 4: Economic status of participants

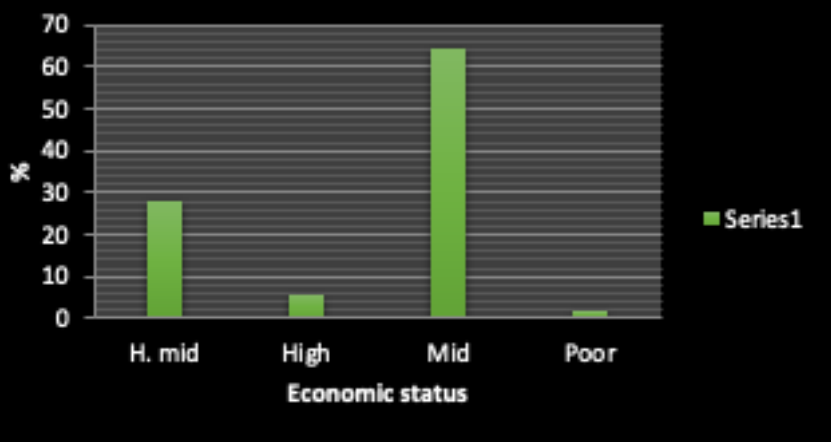

Graph 5: participant's Habits/like to consume

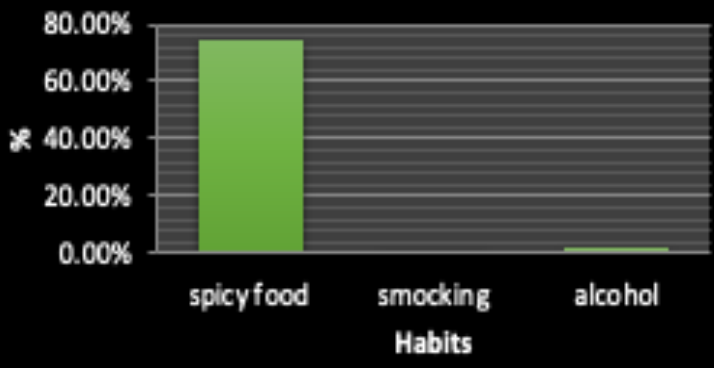

Graph 6: Sleep pattern of participants

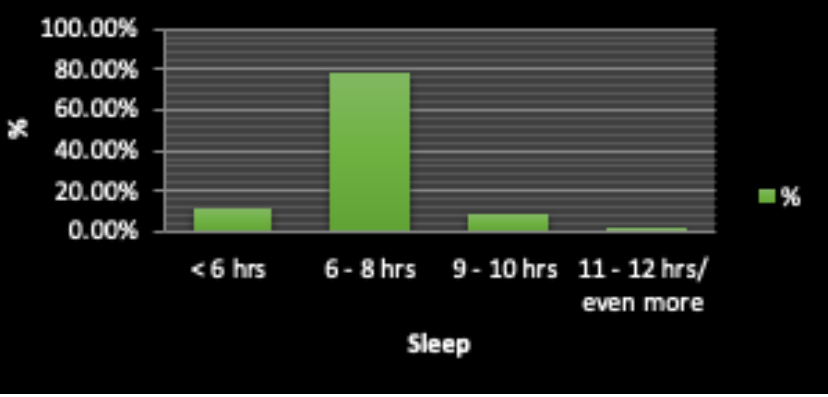

Graph 7: Anxiety problem and doing exercise by participants

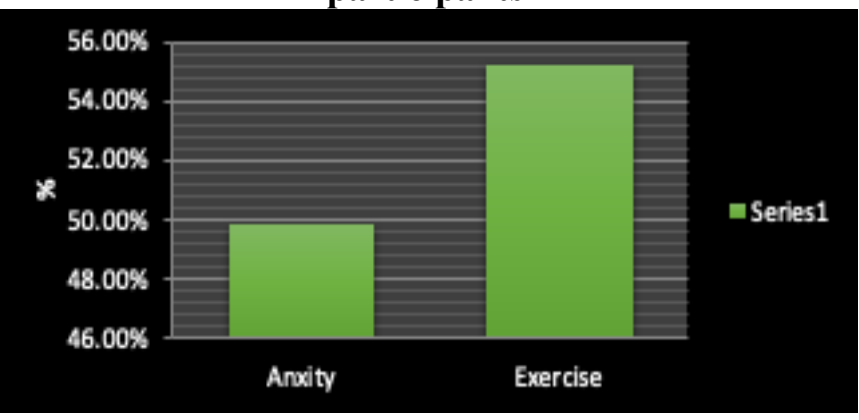

Graph 8: Menarche age of participants

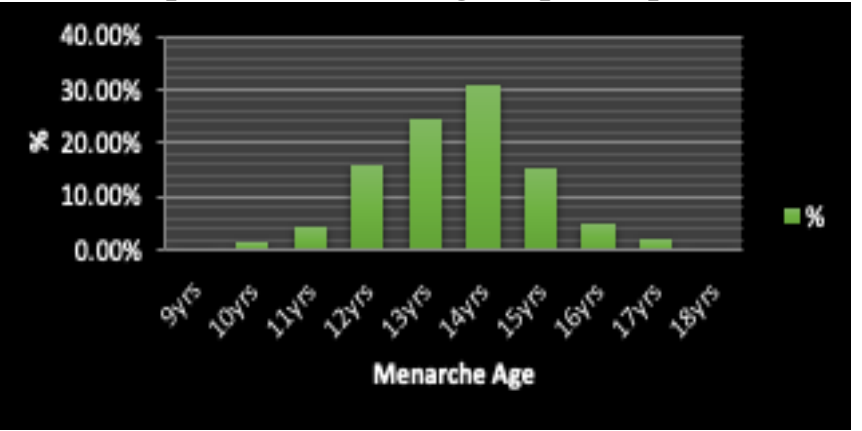

\section{Graph 9: Menstrual cycle of participants}
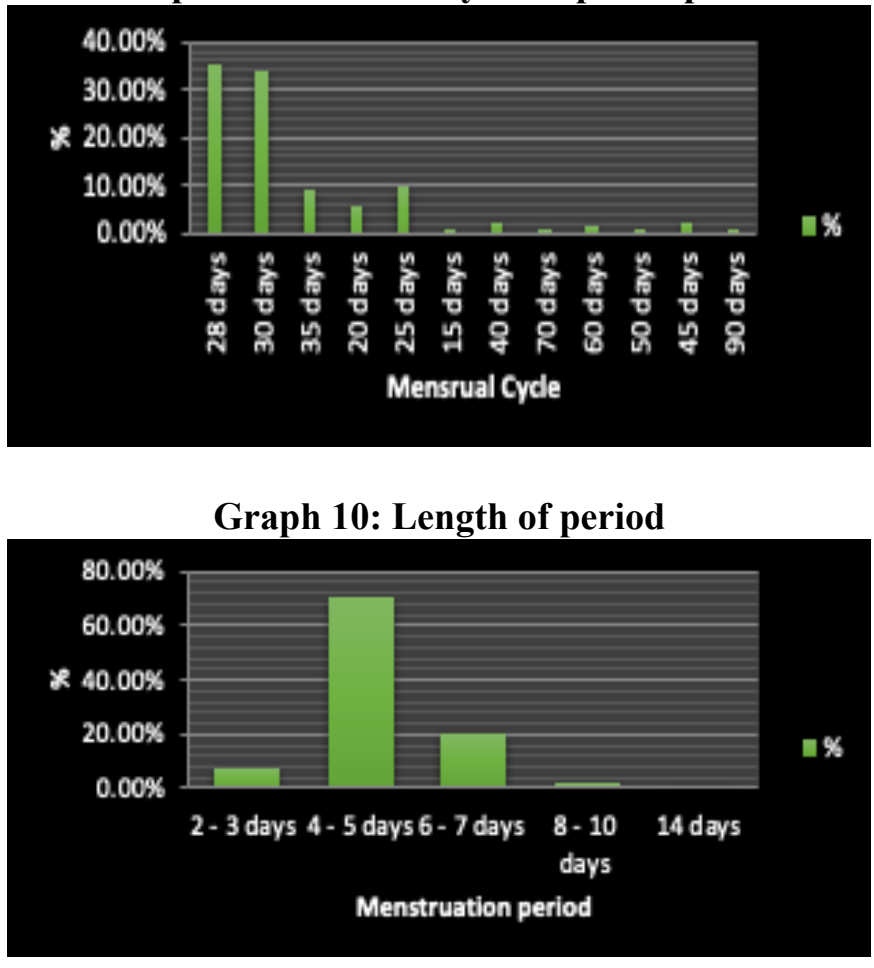

\section{Graph 11: Bleeding type}

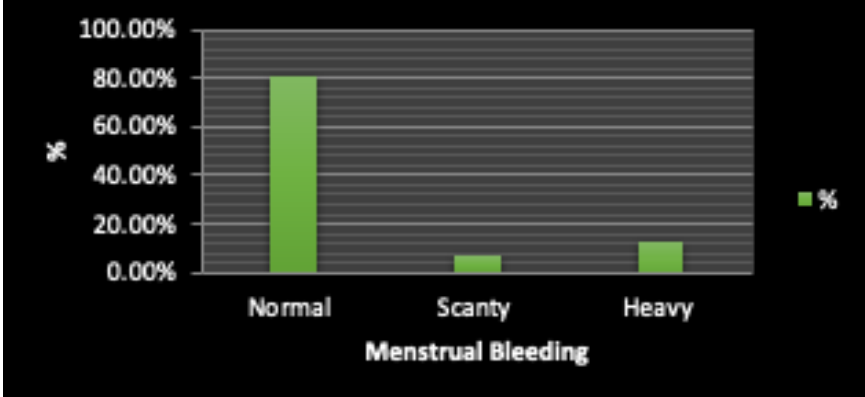

Graph 12: Required pads per day

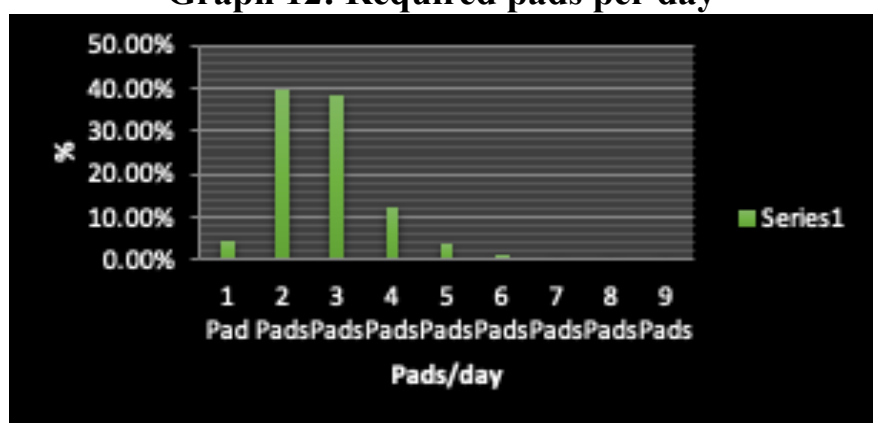

Graph 13: Source of knowledge regarding menstruation

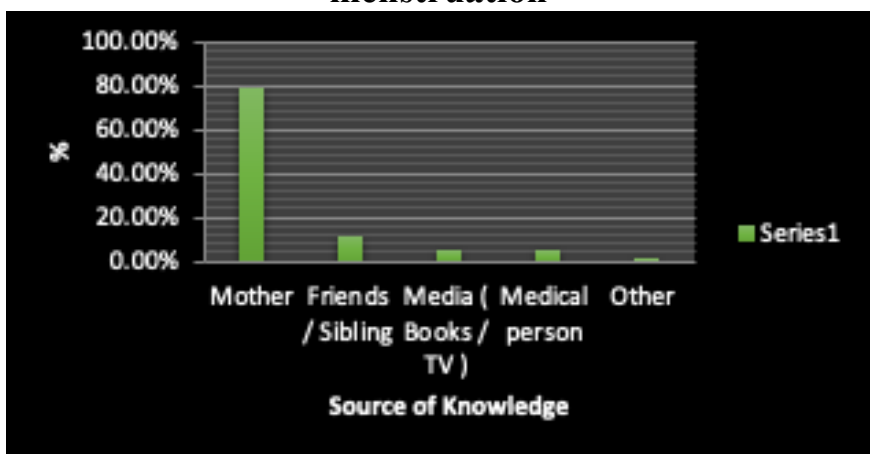




\section{Graph 14: Associated symptoms of dysmenorrhoea}

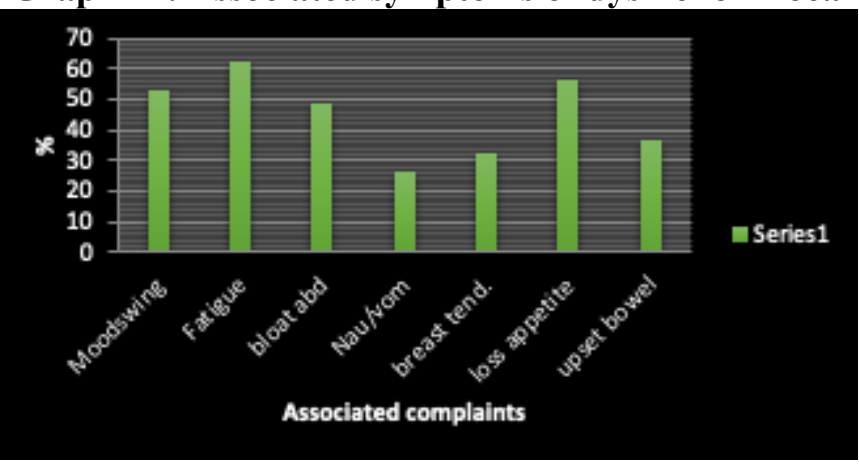

\section{Graph 15: Period of dysmennorhoea}

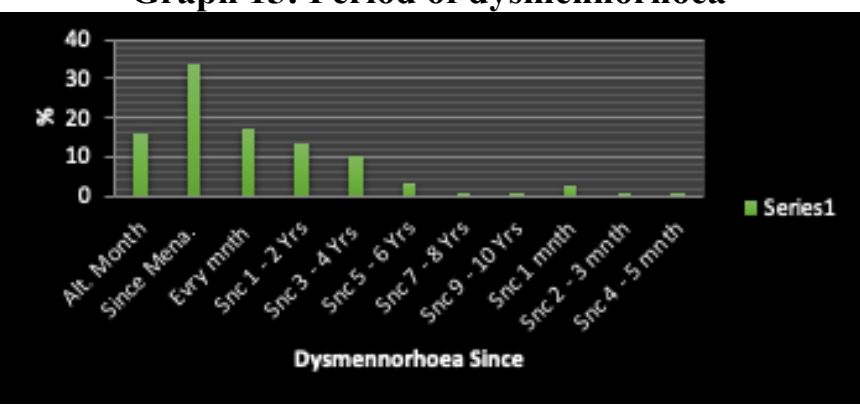

Graph 16: Duration of menstrual pain

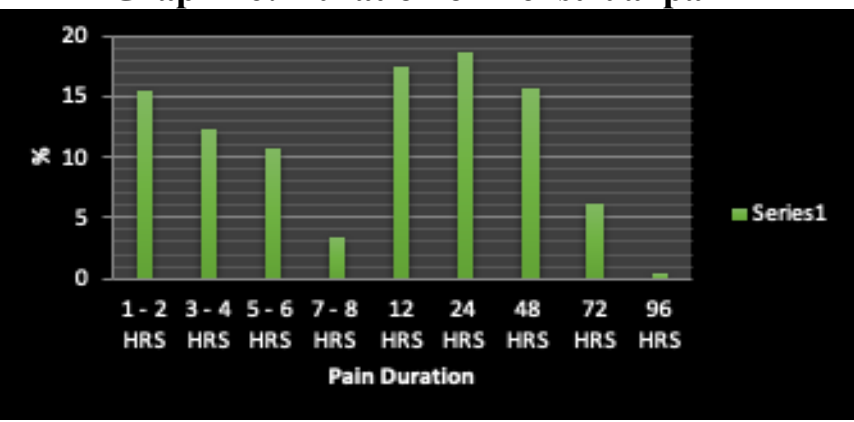

Graph 17: Menstrual pain starting day

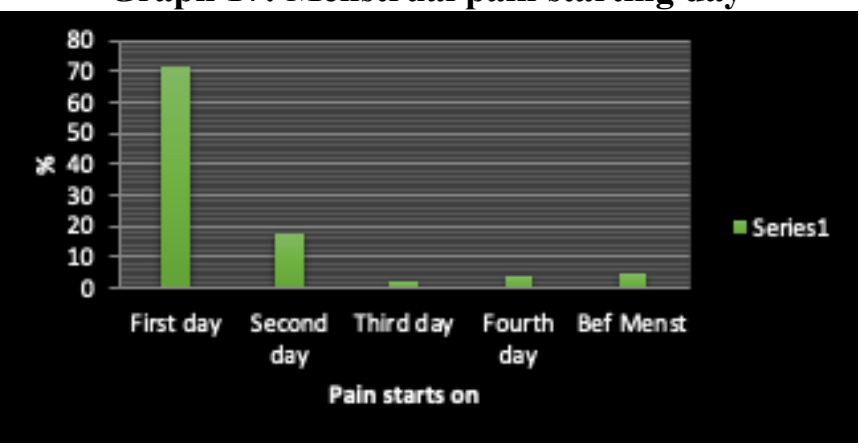

\section{Graph 17: Medical assistance during} dysmenorrhoea

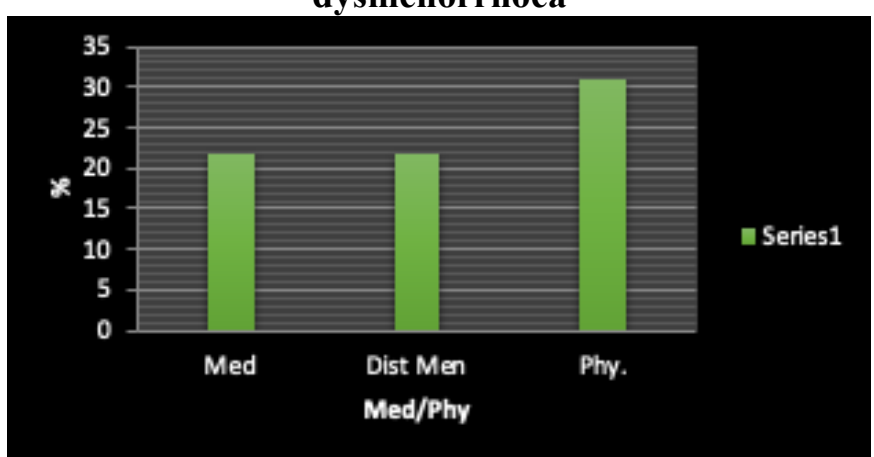

Graph 18: Performance affected by dysmenorrhoea

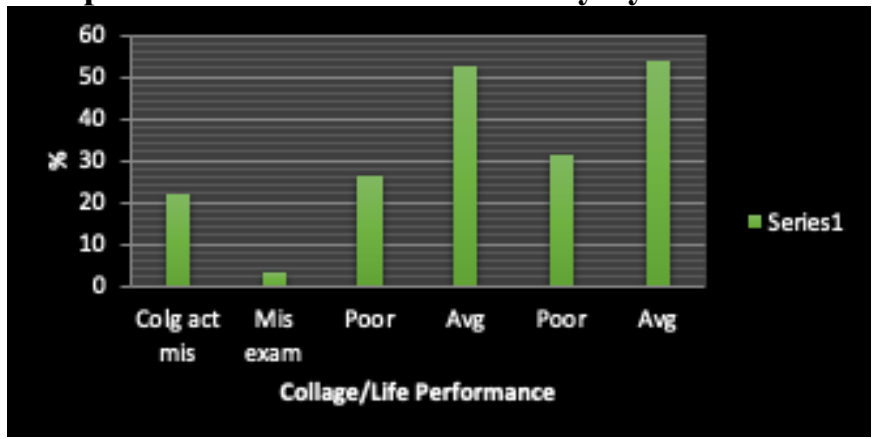

Graph 19: Intensity of menstrual pain

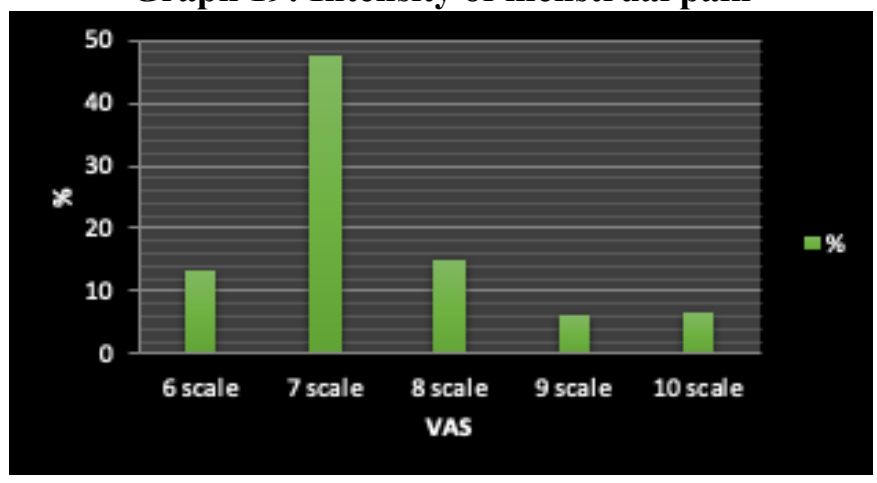

